\title{
Conceptual thresholds in health professional education research and scholarship
}

\author{
K. Kumar ${ }^{1}$, S. King ${ }^{1} \&$ A. Seymour-Walsh', 2
}

\begin{abstract}
Healthcare professionals (HCPs) are increasingly undertaking health professional education (HPE) research and scholarship. This discussion paper highlights key transition points experienced by HCPs newly engaging in HPE research and scholarship, using conceptual thresholds as a theoretical lens. The identified thresholds are: (1) recognising limits, (2) navigating discourses and (3) negotiating identities, and our paper evidences the epistemic, discursive and existential repositioning underpinning these thresholds. Supporting HCPs to successfully navigate the rich and vibrant world of HPE research and scholarship requires a multi-faceted strategy involving individual upskilling, coconstruction of resources and strategies, and enhancing the invitational quality of HPE research activities, environments and communities.
\end{abstract}

Keywords: health professional education research; conceptual thresholds; faculty development

\section{Introduction}

Since Boyer (1990) called for teaching to be positioned as a form of scholarly practice, there has been a growing emphasis on scholarship and research in health professional education (HPE) (McGaghie, 2009). Increasing numbers of healthcare professionals (HCPs) are engaging in educational research as part of their professional growth and advancement (McGaghie, 2009; Steinert, 2014; Tavakol et al., 2008). When HCPs

\footnotetext{
Prideaux Discipline of Clinical Education, College of Medicine and Public Health,

Flinders University, Adelaide, South Australia

2 SA Ambulance Service, Government of South Australia
}

\section{Correspondence}

Dr Koshila Kumar

Prideaux Discipline of Clinical Education

Flinders University

Sturt Road

Bedford Park, South Australia 5042

Australia

Tel: +61 872218891

Email: koshila.kumar@flinders.edu.au 
engage in HPE research and scholarship, it professionalises education within health (McGaghie, 2009), however the journey is not without its challenges.

For example, HCPs' engagement with HPE research and scholarship has been compared to entering alien territory (Kneebone, 2002; McGaghie, 2009) and described as being fraught with disorientation, disquiet and dissonance (Denniston \& Tai, 2020; Kneebone, 2002; Thomas, 2019). Indeed, in the HPE research context, HCPs face the prospect of relinquishing the safety and security of what they know and hold dear (Kneebone, 2002; Thomas, 2019). Whilst there are many descriptive accounts of HCPs' experiences as they newly engage in HPE research, there is a dearth of theoretically informed interpretations. Various authors have identified the importance of using theory in HPE research to provide a deeper understanding of phenomena (Rees \& Monrouxe, 2010; Samuel et al., 2020). Therefore, we set out to theorise HCPs' experiences in HPE research and scholarship to better illuminate their experience and understand how to improve the support for new and emerging HPE researchers and scholars.

We used threshold concepts (TCs) (Meyer \& Land, 2005, 2006) as the theoretical lens for this inquiry because it makes explicit the taken-for-granted ways of seeing, thinking, doing and being that underpin what it means to know, or "knowing-in-action" (Schön, 1995). TCs refer to concepts that are problematic for novices but which concurrently provide "portals" of entry into a new discipline (Neve et al., 2016, p. 851). TCs are central to the mastery of a field, i.e., once mastered, these can pave the way for profoundly new and different understandings, interpretations and perspectives (Meyer \& Land, 2005, 2006). TCs are conceptualised as being transformative, troublesome, irreversible, integrative, bounded, liminal, reconstitutive and discursive (Meyer \& Land, 2005, 2006), and these characteristics have been extensively described elsewhere (Neve et al., 2016).

TCs are traditionally regarded as discrete concepts, or knowledge units. However, they have also been framed as "conceptual thresholds" (Keefer, 2015, p. 25), or transition points, where novices "make learning leaps, develop their identities, and start to work at a critical, conceptual and creative level" (Wisker \& Savin-Baden, 2009, p. 236). This reframing shifts the focus to process as opposed to concepts. While this theoretical framework has been applied to exploring the experience of novice doctoral researchers (Keefer, 2015; Kiley \& Wisker, 2009; Wisker, 2015) and HCPs (Clouder, 2005; Neve et al., 2016), it has not been used in the context of HPE research and scholarship.

In this paper, we frame the experiences of new and emerging HPE researchers and scholars using conceptual thresholds as a theoretical lens.

\section{Conceptual thresholds for HCPs new to HPE research and scholarship}

We have identified three conceptual thresholds, or transition points, encountered by HCPs as they engage in HPE research and scholarship. The identification of these thresholds has been informed by the literature; our experiences of working with, 
supervising and mentoring HCPs in an HPE postgraduate program; and our transition experiences into HPE research and scholarship. KK is a mid-career academic with a background in general education, who coordinates a postgraduate HPE course and is involved in HPE scholarship and research capacity building at an institutional and national level; SK is an early-career academic with a background in education, who leads the student coaching and research capacity building portfolios in a Doctor of Medicine program; and ASW is an early-career academic with a background in paramedicine, who is involved in paramedic education and paramedic research capacity building. Collectively, we represent diverse perspectives and experiences. Each conceptual threshold we have identified is discussed below and illustrated with a vignette (see Boxes 1-3).

\section{Recognising limits}

This conceptual threshold emphasises the shifts in knowledge and knowing experienced by those new to HPE research and scholarship. During their education and training, HCPs are socialised into a clinical worldview (or paradigm) (Kneebone, 2002; Ng, 2013). In this clinical paradigm, there is a specific "epistemic" view of knowledge as logical, objective, measurable and amenable to prediction, control and replication (Irby, 1990; Kuper \& D'Eon, 2011). Additionally, the solutionist nature of healthcare (Nisbet et al., 2020; Schuwirth \& Durning, 2018; Thomas, 2019) means that HCPs are socialised to highly value problem solving and problem management. As highlighted in Susie's vignette (see Box 1), the clinical paradigm informs how she thinks about research, what she values and what she brings into the HPE research context. In line with this, it appears that Susie is constructing a project to apply a solution to an educational problem and objectively measure the impact of the solution (see Box 1).

\section{Box 1}

\section{Susie the Staff Specialist}

Susie is a director of clinical training at a busy metropolitan hospital. She is undertaking a postgraduate qualification in medical education and has recently commenced her first educational research project. Susie plans to develop and pilot a simulation-based education workshop for junior doctors on managing deteriorating patients and working in multidisciplinary teams. She plans to use a validated survey instrument before and after the workshop to address the issues that she has identified with the transition to clinical practice amongst junior doctors.

While HCPs remain safely ensconced in the clinical paradigm, they mostly do not need to articulate, examine, defend or reframe their clinical worldview, as this is shared and accepted by the community around them. However, when HCPs engage in HPE and HPE research, they can experience an epistemic challenge, or what Kneebone (2002) refers to as a "clash of world views_ - or rather, a clash between the comforting solidity of orthodox 'science' and the fluidity of those disciplines which challenge their own paradigms as a matter of course" (p. 514). Navigating this conceptual threshold requires 
HCPs such as Susie to recognise that they have been "indoctrinated and invested in the positivist paradigm of quantitative research" (Thomas, 2019, p. 3). This can be difficult, as it requires HCPs to do multiple things. On one hand, HCPs will need to disentangle their prior clinical knowledge, assumptions, discourses, approaches and identities (Kneebone 2002; Thomas, 2019). On the other hand, HCPs will need to develop an understanding of unfamiliar and counterintuitive knowledge, values and practices (Schuwirth \& Durning, 2018), including shifting their perspectives about knowledge (Schuwirth \& Durning, 2018) and focus towards problem exploration and investigation (Bunniss \& Kelly, 2010; Regehr, 2010).

\section{Navigating discourses}

This conceptual threshold emphasises the communicative and discursive shifts experienced by novice HPE researchers and scholars. Discourse refers to context-specific patterns of language use (Woodward-Kron, 2020). Healthcare practices, events and activities are constituted in discourse and mediated by a specific type of and approach to language and communication (Sarangi, 2010; Woodward-Kron, 2020). HCPs are socialised into these communicative and discursive practices through their undergraduate education and postgraduate health-oriented training, clinical experiences and continuing professional development. Naturally, these communicative practices and discourse inform how HCPs frame and approach research within HPE. This is evident in Nur's vignette (see Box 2), where she is applying a more objective and distanced approach to representing what she has found in the literature.

\section{Box 2}

\section{Nur the Rural Nurse}

Nur is a highly experienced nurse preceptor in a rural hospital setting. Her research project explores nurse educators' experience of undertaking continuing professional development in rural health services. Nur has just completed the first draft of her literature review and, with the aid of several critical appraisal tools, has comprehensively evaluated the quality of the papers she has read. However, Nur's supervisors want her to undertake a more extensive interpretation of the "themes" in the literature and draw on her professional experiences to craft an authentic and persuasive story that does justice to her research interests and concerns of context and is better situated within a broader international conversation. Nur finds this challenging, as she does not feel she has a good grasp on the contemporary international conversation on her topic. She is also unsure about what it means to "craft a research story", as she been trained to think about and approach research writing in a more objective way.

Just as HCPs must navigate an epistemic threshold, they must also navigate a social and discursive threshold when they engage in HPE research and scholarship. In the HPE domain, HCPs will be "joining a new discourse community, with its concomitant 
texts and discursive practices" (Woodward-Kron, 2020, p. 64). This requires learning the jargon of educational research (Scott et al., 2015) and becoming more comfortable with HPE and scholarly conventions, the social and discursive practices of the HPE community and the corpus of HPE literature. Engaging with this new community requires $\mathrm{HCPs}$ to not only recognise new discourses and discursive practices but also to strategically utilise these to establish a compelling, coherent, critical and credible voice in a new field (Lingard \& Watling, 2016). Moreover, since HCPs occupy an "outsider" position in HPE research and scholarship, at least at the beginning (Mann, 2011), they may lack the social capital, which is the influence acquired and accumulated through social networks (Hu et al., 2015), to navigate the social, relational, cultural and political dimensions of HPE research and scholarship (Albert, 2004). This means that novices will need to expend greater effort to establish their credibility, authority and legitimacy in the HPE field (Varpio, 2018).

\section{Negotiating identities}

This threshold emphasises the deep-seated existential changes that HCPs can experience as they engage in HPE research and scholarship. Just as HCPs enter HPE research with deeply ingrained worldviews about knowledge and knowing and discourses, they also typically arrive with a strong clinical identity and sense of self. While some HCPs may also have an emerging or established identity as a clinical educator or supervisor, very few will have a distinct self-concept related to educational research (Kumar et al., 2011; Thomas, 2019). Strongly held professional identities can hamper the development of newer identities (Smith \& Boyd, 2012), especially where the demands and expectations of each role and identity can be seemingly contradictory (Stoddard \& Brownfield, 2016). Attempts to reconcile different self-concepts are associated with different consequences for the individual (Cantillon et al., 2019; Thistlethwaite et al., 2016). As we can see from Pete's vignette (see Box 3), the transition into HPE involves considerable identity work by HCPs, especially those who have multiple professional allegiances and affiliations. In Pete's vignette, we can also see elements of the epistemic and discursive conceptual thresholds, highlighting the interrelatedness of these thresholds and the multiple burdens experienced by HCPs newly engaging in HPE research and scholarship.

The identity transitions experienced by HCPs within HPE research and scholarship is complex. For example, HCPs will find themselves shifting from being a knowledgeable and expert clinician and/or clinical leader to a novice researcher and scholar. They also go from being a skilful clinical problem solver to an educational problem investigator and curator. Additionally, as outlined earlier, HCPs will certainly experience a transition from being a clinical insider to HPE research outsider (Mann, 2011). What this threshold reveals is that HCPs who are new to HPE research and scholarship will encounter multiple existential challenges (Keefer, 2015; Thistlethwaite et al., 2016). 


\section{Box 3}

\section{Pete the Paramedic}

Pete is an experienced emergency ambulance paramedic currently taking a break from his clinical role. He is finalising his doctoral HPE research project, which qualitatively examines the feedback practices of paramedic supervisors in the ambulance service. Pete has recently had his first peer reviewed HPE manuscript accepted for publication and feels confident about the progress he is making in establishing his scholarly profile in HPE. In contrast, in recent discussions with the ambulance service about his research, Pete has faced some tough questions about the rigour and utility of his work. These contrasting experiences have left Pete questioning who he now is, where he belongs and, indeed, how he can reconcile his clinical and educational self and navigate his way between and within multiple professional communities.

\section{Discussion}

By using conceptual thresholds as an interpretive lens, this paper highlights that HCPs who are newly engaging in HPE research and scholarship experience three transition points (recognising limits, navigating discourses and negotiating identities), which are underpinned by epistemic, discursive and existential repositioning. This highlights that an HCP's journey into HPE research and scholarship is not only characterised by changes in knowledge and expertise but also shifts in their status, feelings of belonging and legitimacy, and identity.

If we were to unpack these conceptual thresholds, we might see that they are bounded (Meyer \& Land, 2005, 2006) at the intersect of clinical practice, education and research (International Working Party to Promote and Revitalise Academic Medicine, 2004). This means a tangible juxtaposition of clinical and educational worldviews, values, discourse practices, communities and self-concepts from all three domains. This can give rise to feelings of liminality or "in-betweeness" and can trigger uncertainty, confusion, frustration and/or doubt for novices (Meyer \& Land, 2005, 2006). Therefore, these transition points are troublesome and challenging for novices to navigate (Meyer \& Land, 2005, 2006). However, as HCPs immerse themselves in HPE research activities and scholarly communities, their thinking, views and understandings, including of self, can profoundly change, highlighting that these thresholds are concurrently reconstitutive and transformative and can pave the way for new ways of knowing, doing, seeing and being. These conceptual thresholds are also interrelated, or integrative, implying that once HCPs have been socialised into particular ways of thinking, discursive practices and identities, they are well positioned to make even stronger links between different elements within the broader HPE field. Finally, these transitions are unlikely to be forgotten by HCPs, thereby highlighting their enduring and irreversible nature (Baillie et al., 2013). 


\section{Implications}

Given the subjective, contextual and contested nature of conceptual thresholds (Milligan \& Wood, 2010), an excellent starting point is for HCPs and their supervisors or mentors to co-construct these transition points together (Cousin, 2010). Fundamentally, this requires a learning climate founded upon partnership (Heyns et al., 2019) and safety (Tsuei et al., 2019), where both experienced researchers (e.g., supervisors, mentors) and novices can analyse and question their own thinking, commensurate with the metacognitive dimension of learning (Flavell, 1979). New and emerging HPE researchers and scholars need to be encouraged and guided not just to articulate their a-priori epistemic views and values $(\mathrm{Ng}, 2013)$ but to share these with supervisors, critical friends and peers as the basis of discussion and learning. Supervisors can role model this metacognitive orientation by being candid (Molloy \& Bearman, 2019) about the epistemic, discursive or existential challenges they may have faced and how they have navigated these. To orient novices to the values of HPE research and scholarship, supervisors can explicitly explain the exploratory nature of HPE research (Bunniss \& Kelly, 2010), its contemplative stance (Thomas, 2019), its focus on problems of practice and how these are identified and framed (Regehr, 2010) and the need to look at local issues from a broader, global perspective (Albert et al., 2007).

Multiple strategies can be used to orient and socialise novice HPE researchers and scholars into the discursive practices and expectations of the HPE community (WoodwardKron, 2020). For example, co-constructing artefacts (e.g., a glossary of key concepts and terms relevant to their research) can help HCPs become familiar with the HPE research terminology and facilitate dialogue with their supervisors and others. Rhetorical devices such as the problem-gap-hook heuristic (Lingard, 2015), rhetorical appeals (Varpio, 2018) and "elevator pitches" (Dzara \& Kesselheim, 2018) can help HCPs be targeted and strategic as they communicate with diverse stakeholders in HPE. As much as possible, HCPs need to be encouraged to immerse themselves in a range of discursive and social relational practices of the HPE research community, spanning small-scale and low-stakes activities (e.g., journal clubs, local seminars), more formal mechanisms (e.g., conferences, professional networks) and informal activities (collaborative activities with peers, peer discussions). It is critical to recognise that the engagement of HCPs in HPE research is not just dependent on their skills but also the affordances for access, participation and attainment within socially constituted practices (Billett, 2001). Therefore, HPE research supervisors, mentors and the professional community need to think about ways to enhance the safety (Tsuei et al., 2019) and invitational quality of various social practices (Billett, 2001).

Finally, identity is integral to the human condition and gives people a sense of purpose. Therefore, it should come as no surprise that supporting HCPs to cultivate a strong identity encompassing HPE research (Kumar et al., 2011; Steinert et al., 2019; van Lankveld et al., 2020) is critical for ensuring their continuing engagement, contribution 
and achievement. HCPs need to be supported to normalise the liminality associated with their transition into HPE research and scholarship. Supervisors can assist by making visible their own identity-related dilemmas (Molloy \& Bearman, 2019) and asking prompting questions that encourage HCPs to reflect upon their values and identify any conflicts that may arise.

\section{Limitations and future considerations}

We acknowledge that conceptual thresholds as a lens privileges a specific philosophical perspective (Meyer \& Land, 2006). Furthermore, the interpretations made in this paper are informed by the collective personal and professional lens of the three authors. Future research can seek to corroborate or extend the thresholds identified in this paper and to explore other theoretical perspectives.

\section{Conclusion}

This theoretically informed paper highlights how the journey of health professionals into HPE research and scholarship is characterised by three key transition points and associated with considerable epistemic, discursive and existential repositioning. Assisting HCPs to successfully access, participate in and attain within the rich and diverse world of HPE research and scholarship requires a multipronged approach involving individual, supervisor and HPE community level strategies.

\section{Acknowledgements}

We sincerely thank Emeritus Professor David Prideaux and Dr Maria Gardiner for their feedback on earlier versions of this paper.

\section{Ethics approvals}

Ethics approval was not required for this research.

\section{Funding and conflict of interest}

The authors have no conflicts of interest to report and received no funding for this work.

\section{References}

Albert, M. (2004). Understanding the debate on medical education research: A sociological perspective. Academic Medicine, 79(10), 948-954. https://doi. org/10.1097/00001888-200410000-00009

Albert, M., Hodges, B., \& Regehr, G. (2007). Research in medical education: Balancing service and science. Advances in Health Sciences Education, 12(1), 103-115. https://doi. org/10.1007/s10459-006-9026-2 
Baillie, C., Bowden, J. A., \& Meyer, J. H. (2013). Threshold capabilities: Threshold concepts and knowledge capability linked through variation theory. Higher Education, 65(2), 227-246. https://doi.org/10.1007/s10734-012-9540-5

Billett, S. (2001). Co-participation: Affordance and engagement at work. New Directions for Adult and Continuing Education, 2001(92), 63-72. https://doi.org/10.1002/ace.41

Boyer, E. (1990). Scholarship reconsidered: Priorities of the professoriate. Carnegie Foundation for the Advancement of Teaching.

Bunniss, S., \& Kelly, D. R. (2010). Research paradigms in medical education research. Medical Education, 44(4), 358-366. https://doi.org/10.1111/j.1365-2923.2009.03611.x

Cantillon, P., Dornan, T., \& De, W. G. (2019). Becoming a clinical teacher: Identity formation in context. Academic Medicine, 94(10), 1610-1618. https://doi.org/10.1097/ ACM.0000000000002403

Clouder, L. (2005). Caring as a "threshold concept": Transforming students in higher education into health (care) professionals. Teaching in Higher Education, 10(4), 505-517. https://doi.org/10.1080/13562510500239141

Cousin, G. (2010). Neither teacher-centred nor student-centred: Threshold concepts and research partnerships. Journal of Learning Development in Higher Education, 2. https://doi.org/10.47408/jldhe.v0i2.64

Denniston, C., \& Tai, J. (2020). Paradigm shifts during higher degrees by research. The Clinical Teacher, 17(1), 98-99. https://doi.org/10.1111/tct.13002

Dzara, K., \& Kesselheim, J. (2018). Going up? Tips for the medical educator's “Elevator Pitch.” Academic Medicine, 93(12), 1884. https://doi.org/10.1097/ ACM.0000000000002393

Flavell, J. H. (1979). Metacognition and cognitive monitoring: A new area of cognitivedevelopmental inquiry. American Psychologist, 34(10), 906-911. https://doi. org/10.1037/0003-066X.34.10.906

Heyns, T., Bresser, P., Buys, T., Coetzee, I., Korkie, E., White, Z., \& Mc Cormack, B. (2019). Twelve tips for supervisors to move towards person-centered research supervision in health care sciences. Medical Teacher, 41(12), 1353-1358. https://doi.or g/10.1080/0142159X.2018.1533241

Hu, W., Thistlethwaite, J., Weller, J., Gallego, G., Monteith, J., \& McColl, G. (2015). "It was serendipity": A qualitative study of academic careers in medical education. Medical Education, 49(11), 1124-1136. https://oi.org/10.1111/medu.12822 
International Working Party to Promote and Revitalise Academic Medicine. (2004). ICRAM (The International Campaign to Revitalise Academic Medicine): Agenda setting. BMJ, 329(7469), 787-789. https://doi.org/10.1136/bmj.329.7469.787

Irby, D. M. (1990). Shifting paradigms of research in medical education. Academic Medicine, 65(10), 622-623. https://doi.org/10.1097/00001888-199010000-00002

Keefer, J. M. (2015). Experiencing doctoral liminality as a conceptual threshold and how supervisors can use it. Innovations in Education and Teaching International, 52(1), 17-28. https://doi.org/10.1080/14703297.2014.981839

Kiley, M., \& Wisker, G. (2009). Threshold concepts in research education and evidence of threshold crossing. Higher Education Research \& Development, 28(4), 431-441. https://doi.org/10.1080/07294360903067930

Kneebone, R. (2002). Total internal reflection: An essay on paradigms. Medical Education, 36(6), 514-518. https://doi.org/10.1046/j.1365-2923.2002.01224.x

Kumar, K., Roberts, C., \& Thistlethwaite, J. (2011). Entering and navigating academic medicine: Academic clinician-educators' experiences. Medical Education, 45(5), 497-503. https://doi.org/10.1111/j.1365-2923.2010.03887.x

Kuper, A., \& D’Eon, M. (2011). Rethinking the basis of medical knowledge. Medical Education, 45(1), 36-43. https://doi.org/10.1111/j.1365-2923.2010.03791.x

Lingard, L. (2015). Joining a conversation: The problem/gap/hook heuristic. Perspectives on Medical Education, 4(5), 252-253. https://doi.org/10.1007/s40037-015-0211-y

Lingard, L., \& Watling, C. (2016). It's a story, not a study: Writing an effective research paper. Academic Medicine, 91(12), e12. https://doi.org/10.1097/ $\underline{\text { ACM.0000000000001389 }}$

Mann, K. V. (2011). Theoretical perspectives in medical education: Past experience and future possibilities. Medical Education, 45(1), 60-68. https://doi.org/10.1111/j.13652923.2010.03757.x

McGaghie, W. C. (2009). Scholarship, publication, and career advancement in health professions education: AMEE Guide No. 43. Medical Teacher, 31(7), 574-590. https://doi.org/10.1080/01421590903050366

Meyer, J., \& Land, R. (2005). Threshold concepts and troublesome knowledge (2): Epistemological considerations and a conceptual framework for teaching and learning. Higher Education, 49(3), 373-388. https://doi.org/10.1007/s10734-0046779-5 
Meyer, J., \& Land, R. (2006). Overcoming barriers to student understanding: Threshold concepts and troublesome knowledge. Routledge. https://doi. org/10.4324/9780203966273

Milligan, A., \& Wood, B. (2010). Conceptual understandings as transition points: Making sense of a complex social world. Journal of Curriculum Studies, 42(4), 487-501. https://doi.org/10.1080/00220270903494287

Molloy, E., \& Bearman, M. (2019). Embracing the tension between vulnerability and credibility: "Intellectual candour" in health professions education. Medical Education, 53(1), 32-41. https://doi.org/10.1111/medu.13649

Neve, H., Wearn, A., \& Collett, T. (2016). What are threshold concepts and how can they inform medical education? Medical Teacher, 38(8), 850-853. https://doi.org/10.3 109/0142159X.2015.1112889

$\mathrm{Ng}$, S. L. (2013). Theory and research in audiology education: Understanding and representing complexity through informed methodological decisions. Journal of the American Academy of Audiology, 24(5), 344-353. https://doi.org/https://doi. org/10.3766/jaaa.24.5.2

Nisbet, G., McAllister, S., Morris, C., \& Jennings, M. (2020). Moving beyond solutionism: Re-imagining placements through an activity systems lens. Medical Education, 55(1), 45-54. https://doi.org/10.1111/medu.14345

Rees, C., \& Monrouxe, L. (2010). Theory in medical education research: How do we get there? Medical Education, 44(4), 334-339. https://doi.org/10.1111/j.13652923.2009.03615.x

Regehr, G. (2010). It's NOT rocket science: Rethinking our metaphors for research in health professions education. Medical Education, 44(1), 31-39. https://doi. org/10.1111/j.1365-2923.2009.03418.x

Samuel, A., Konopasky, A., Schuwirth, L. W., King, S. M., \& Durning, S. J. (2020). Five principles for using educational theory: Strategies for advancing health professions education research. Academic Medicine, 95(4), 518-522. https://doi.org/10.1097/ ACM.0000000000003066

Sarangi, S. (2010). Practising discourse analysis in healthcare settings. In I. Bourgeault, R. Dingwall, \& R. de Vries (Eds.), The SAGE handbook of qualitative methods in health research (pp. 397-416). Sage. https://www.doi.org/10.4135/9781446268247.n21 
Schön, D. A. (1995). Knowing-in-action: The new scholarship requires a new epistemology. Change: The Magazine of Higher Learning, 27(6), 27-34. https://doi.org /10.1080/00091383.1995.10544673

Schuwirth, L. W., \& Durning, S. J. (2018). Educational research: Current trends, evidence base and unanswered questions. Medical Journal of Australia, 208(4), 161-163. https://doi.org/10.5694/mja17.00805

Scott, K., Caldwell, P., \& Schuwirth, L. (2015). Ten steps to conducting health professional education research. The Clinical Teacher, 12(4), 272-276. https://doi. org/10.1111/tct.12287

Smith, C., \& Boyd, P. (2012). Becoming an academic: The reconstruction of identity by recently appointed lecturers in nursing, midwifery and the allied health professions. Innovations in Education and Teaching International, 49(1), 63-72. https://doi.org/10. $\underline{1080 / 14703297.2012 .647784}$

Steinert, Y. (2014). Faculty development in the health professions: A focus on research and practice (Vol. 11). Springer. https://doi.org/10.1007/978-94-007-7612-8

Steinert, Y., O’Sullivan, P. S., \& Irby, D. M. (2019). Strengthening teachers' professional identities through faculty development. Academic Medicine, 94(7), 963-968. https://doi.org/10.1097/ACM.0000000000002695

Stoddard, H. A., \& Brownfield, E. D. (2016). Clinician-educators as dual professionals: A contemporary reappraisal. Academic Medicine, 91(7), 921-924. https://doi. org/10.1097/ACM.0000000000001210

Tavakol, M., Murphy, R., Rahimi Madiseh, M., \& Torabi, S. (2008). The involvement of clinicians in medical education research. Quality in Primary Care, 16(5), 335-340. https://pubmed.ncbi.nlm.nih.gov/18973714/

Thistlethwaite, J., Kumar, K., \& Roberts, C. (2016). Interprofessionalism and professional identity formation. In R. Cruess, S. Cruess, \& Y. Steinert (Eds.), Teaching medical professionalism: Supporting the development of a professional identity (pp. 140-154). Cambridge University Press. https://doi.org/10.1017/ CBO9781316178485.012

Thomas, J. (2019). The clinician educator as qualitative researcher. The Clinical Teacher, 16(6), 646-648. https://doi.org/10.1111/tct.12977

Tsuei, S. H-T., Lee, D., Ho, C., Regehr, G., \& Nimmon, L. (2019). Exploring the construct of psychological safety in medical education. Academic Medicine, 94(11S), S28-S35. https://doi.org/10.1097/ACM.0000000000002897 
van Lankveld, T., Thampy, H., Cantillon, P., Horsburgh, J., \& Kluijtmans, M. (2020). Supporting a teacher identity in health professions education: AMEE Guide No.132. Medical Teacher, 43(2), 1-13. https://doi.org/10.1080/0142159X.2020.1838463

Varpio, L. (2018). Using rhetorical appeals to credibility, logic, and emotions to increase your persuasiveness. Perspectives on Medical Education, 7(3), 207-210. https://doi. org/10.1007/s40037-018-0420-2

Wisker, G. (2015). Developing doctoral authors: Engaging with theoretical perspectives through the literature review. Innovations in Education and Teaching International, 52(1), 64-74. https://doi.org/10.1080/14703297.2014.981841

Wisker, G., \& Savin-Baden, M. (2009). Priceless conceptual thresholds: Beyond the "stuck place" in writing. London Review of Education, 7(3), 235-247. https://doi. org/10.1080/14748460903290207

Woodward-Kron, R. (2020). Let's talk about discourse analysis for health professional education: What, why and how. Focus on Health Professional Education: A Multidisciplinary Journal, 21(2), 63. https://doi.org/10.11157/fohpe.v21i2.470 